\title{
TANTANGAN DAN PROSPEK PEMANFAATAN DATA DARING DALAM MENDUKUNG KUALITAS ESTIMASI DATA PDRB
}

\section{(Challenges and Opportunities for Implementing Online Data Collection to Improve the Quality of GRDP Estimates)}

\author{
Elfryanty Novita ${ }^{1}$
}

1) Badan Pusat Statistik Kota Sorong, Papua Barat

E-mail: elfri@bps.go.id

\begin{abstract}
ABSTRAK
Data dasar untuk estimasi Produk Domestik Regional Bruto (PDRB) regional (provinsi dan kabupaten/kota) sektor jasa terbatas sehingga data daring dapat digunakan sebagai pendukung estimasi tersebut. Data komplemen dapat dikumpulkan melalui survei dengan memanfaatkan internet sebagai media dan memodifikasi daftar pertanyaan pada kuesioner. Metode data daring memiliki prospek menjanjikan meskipun terdapat juga tantangannya dalam revolusi industri 4.0. Adapun tujuan penulisan adalah untuk mengkaji tantangan dan peluang data daring sebagai sumber estimasi PDRB regional sektor jasa-jasa untuk kualitas lebih baik. Kajian menggunakan metode kajian literatur dengan pendekatan konseptual-tradisional dan observasi yang didasarkan pengalaman penulis. Berdasarkan studi dokumentasi, penerapan data daring yang dimaksud hanya pada penambahan cakupan sampel survei khusus triwulanan dan tahunan yang menggunakan metode purposive sampling untuk pemilihan responden. Potensi respon rate yang rendah, faktor keamanan online dan kecenderungan bias data akan menjadi kendala dalam mencapai optimalisasi manfaat. Namun, bila desain sampel dan modifikasi kuesioner serta profiling information responden diperhatikan, akan dapat meminimalisir hal tersebut. Meskipun demikian, perlu dilakukan studi lebih lanjut pada faktor akurasi data yang dihasilkan agar data pendukung tersebut dapat berkontribusi dalam peningkatan kualitas estimasi PDRB regional.
\end{abstract}

Kata Kunci: PDRB/Produk Domestik Regional Bruto, Data Daring, Survei online, Estimasi

\section{ABSTRACT}

Basic data for estimation of GRDP (Gross Regional Domestic Product) for regional scope (province and regency/municipality) specifically for industrial services is limited. Therefore, online data collection can be used as the supplementary data for this purpose. This supplementary is collected by services survey using internet as its media and we modify the list of questions in its questionnaire. The online method has gained promising prospects although it still has its challenges in industrial revolution 4.0. This study aims to examine the challenges and opportunities of online data as the data resource for a better estimate of GRDP for services sector. The method used is the literature review with the conceptual-traditional approach and the observation according to the authors' experiences. However, based on the documentation study, the implementation of online data is referred to the increase of sample size for quarterly and annual services survey using purposive sampling for its samples' choice. The possibility of low response rate, the online security and the tendency for biased estimation would be challenges encountered to achieve the optimum benefits. Hence, we can minimize these by modifying the design sampling and questionnaires also we should concern about the profiling information of potential respondents. Despite its prospects, the further study for the accuracy of data online should be push forward so its result would contribute to increase the quality rate of GRDP for regional scale.

Keywords: Gross Regional Domestic Product, Online data, online survey, Estimation

\section{PENDAHULUAN}

Produk Domestik Regional Bruto (PDRB) merupakan salah satu jenis data yang dihasilkan oleh Badan Pusat Statistik (BPS) yang memberikan gambaran mengenai kondisi perekonomian wilayah pada level regional (provinsi dan kabupaten/kota). Hingga tahun 2020, data ini diestimasi menggunakan dua pendekatan, yaitu sisi produksi (PDRB menurut Lapangan Usaha) dan sisi konsumsi (PDRB menurut Penggunaan). Tidak seperti pada level nasional, data-data dasar dan data pendukung untuk penghitungan PDRB level regional termasuk cukup terbatas dan cenderung 
fluktuatif dalam ketersediaannya karena data-data makro lebih mudah dikumpulkan dibandingkan data mikro. Umumnya survei-survei khusus yang dikumpulkan oleh BPS Provinsi dan BPS Kabupaten/Kota di Indonesia memiliki cakupan untuk level nasional saja (sebagai data input untuk estimasi PDB Indonesia). Sementara itu, data dasar yang dikompilasi dari instansi non-BPS misalnya pemerintah daerah memiliki kekurangan dalam ketepatan waktu dan kontinuitas dalam ketersediaan data. Kendala ini terutama menjadi tantangan tersendiri dalam estimasi PDRB dengan pendekatan produksi karena sektor-sektor jasa merupakan sektor yang sangat sulit diestimasi mengingat outputnya bersifat intangible.

Pandemi Covid-19 sejak Maret 2020 juga makin meningkatkan besarnya tantangan dalam penghitungan PDRB regional, terutama level provinsi karena penyajian data ini dilakukan secara triwulanan. Selain berimbas pada metode pengumpulan data yang beralih ke metode daring (dalam jaringan/online), pandemi ini juga berdampak pada tingkat akurasi data yang dikumpulkan karena potensi missing values pada beberapa sektor usaha yang kolaps. Sektor pariwisata menjadi sektor yang paling terdampak dengan adanya penutupan tempat-tempat wisata, aktivitas layanan dan kunjungan wisata yang terhenti (Taufik dan Ayuningtyas, 2020). Hal ini tentu akan menjadi tantangan dalam estimasi perkiraan dampak Covid-19 terhadap sektor-sektor yang terkait dengan industri pariwisata.

Keterbatasan pada data pokok yang dikompilasi dari stakeholder di luar BPS seperti SKPD (Satuan Kerja Perangkat Daerah) misalnya, perlu diatasi dengan informasi pendukung lainnya yang relevan. Salah satunya dengan supplementary survey, yaitu pengumpulan data pendukung melalui online/daring yang difokuskan pada indikator-indikator penting terkait produksi dan harga. Meskipun demikian, metode ini masih diragukan tingkat akurasinya (Toma, Heinrich, \& Bauer, 2011), terbatas untuk survei-survei yang bersifat nonprobability sampling yang cenderung bias (Terhanian, 2016), dan memerlukan profiling information dalam pemilihan sampel/responden yang tepat (Revilla, \& Ochoa, 2018). Supplemen data daring yang digunakan perlu disusun lebih spesifik pada data-data dasar yang sangat terbatas atau kurang reliabel karena faktor-faktor tertentu seperti faktor musiman, komoditas timbul tenggelam dan sebagainya.

Paper ini bertujuan untuk memberikan kajian mengenai tantangan penerapan data daring sebagai data pendukung untuk peningkatan kualitas penghitungan PDRB regional baik PDRB Provinsi maupun PDRB Kabupaten/Kota dari berbagai literatur pustaka dan studi empiris hasil observasi penulis. Selain itu, juga mengetahui prospek implementasi data daring demi peningkatan kualitas estimasi data PDRB.

\section{TINJAUAN PUSTAKA}

Produk Domestik Regional Bruto (PDRB) menurut konsep BPS adalah semua barang dan jasa yang diproduksi sebagai hasil dari kegiatan ekonomi di suatu wilayah dengan mengabaikan sumber kepemilikan faktor produksi dalam produksi tersebut. Pendapatan yang dihasilkan dari PDRB merupakan pendapatan domestik. PDRB memiliki tiga pendekatan dalam penghitungannya, yaitu dari sisi produksi, pengeluaran dan pendapatan. Hingga kini, BPS mengestimasi PDRB pada level provinsi dan kabupaten/kota menggunakan pendapatan produksi dan pengeluaran.

Selama ini BPS melaksanakan survei-survei khusus yang dilaksanakan secara tatap muka, bertujuan untuk menghasilkan rasio NTB (Nilai Tambah Bruto) atau faktor input yang digunakan untuk mengestimasi output. Nilai Tambah Bruto (NTB) adalah ukuran yang nilai yang diciptakan melalui proses produksi, dihitung dari selisih antara nilai produksi (output) dan biaya antara (biaya yang habis digunakan dalam proses produksi). NTB juga dapat dihitung dari perkalian output dan rasio NTB, selanjutnya penjumlahan dari seluruh nilai tambah yang dihasilkan dari kegiatan ekonomi di suatu wilayah menghasilkan angka PDRB. Akan tetapi, jumlah sampel yang dialokasikan belum cukup jika digunakan untuk level regional.

Beberapa pendekatan lain terkait estimasi PDRB diantaranya trend ketenagakerjaan dan konsumsi penduduk yang diukur melalui aplikasi mobile internet yang dapat digunakan untuk 
mengukur tingkat pertumbuhan aktivitas perekonomian (Dong, dkk, 2016). Meskipun demikian, pendekatan ini hanya bersifat membangun indikator ekonomi praktis karena keuntungan seperti coverage rate yang lebih tinggi, lebih terstruktur dan tidak sensitif terhadap perubahan pada asumsi (Toole, dkk, 2015 dalam Dong, dkk, 2016). Survei khusus yang dibangun untuk memperoleh indikator dalam estimasi PDRB sektor jasa-jasa menggunakan pemilihan sampel secara non-probability sampling dengan metode purposive.

Pengumpulan data melalui daring yang dibangun untuk estimasi PDRB sektor jasa-jasa lebih mengarah ke survei online yang didefinisikan sebagai kuesioner dalam format digital atau kertas elektronik menggunakan teknologi ICT/Information communication technology (Callegaro, dkk, 2015). Akan tetapi, survei online rentan dengan masalah akurasi dalam jawaban responden (Gao, House dan Xie, 2013) dan isu-isu seputar metodologi (Vehovar dan Manfreda, 2016 dalam Fielding, Lee, \& Blank, 2016).

Menurut Terhanian, dkk (2016), survei-survei yang dikumpulkan melalui metode nonprobability sampling dapat ditingkatkan akurasinya melalui Optimization Method menggunakan algoritma yang dikhususkan sesuai dengan tujuan pengumpulan data dengan meningkatkan jumlah sampel atau faktor penimbang. Metode tersebut menggunakan benchmark AGR (usia, gender dan wilayah) untuk pemilihan responden dikombinasikan dengan karakteristik individu lainnya, misalnya pendidikan, status perkawinan, jenis pekerjaan dan lamanya waktu dihabiskan untuk aktivitas online. Akan tetapi, Revilla, dan Ochoa (2018) merekomendasikan pemilihan sampel yang memiliki profiling information pada calon responden berdasarkan jejak digital secara panel misalnya profil usaha. Hal ini dimaksudkan agar responden yang ditargetkan bersifat representatif terhadap populasi.

\section{METODE PENELITIAN}

Adapun metode analisis yang digunakan adalah kajian literatur melalui pendekatan konseptual-tradisional. Analisis yang dihasilkan bersifat deskriptif kualitatif dengan mengkaji tantangan dan peluang penerapan data daring sebagai data pendukung dalam penghitungan PDRB regional pendekatan produksi untuk sektor-sektor jasa. Pendekatan dalam kajian ini dilakukan dengan melakukan sintesis pengetahuan mengenai tantangan dan prospek pengumpulan data daring untuk memperkuat estimasi PDRB regional.

Data daring yang dikaji terbatas untuk survei non-probability sampling dengan target responden adalah unit institusi atau pelaku kegiatan ekonomi yang memiliki potensi pangsa pasar yang relatif dominan dalam sektor usaha yang sejenis. Pendekatan metode kajian adalah melalui studi dokumentasi yang berasal dari karya ilmiah seperti artikel, makalah, jurnal, dan lainnya (Rany, dkk, 2020). Cakupan kajian bersifat objektif berdasarkan studi literatur dan pendekatan studi empiris mengenai data daring mencakup tantangan dan potensi implementasinya untuk perbaikan kualitas data estimasi PDRB regional di masa mendatang. Studi empiris yang dimaksud berdasarkan observasi pengalaman penulis dalam estimasi PDRB regional (provinsi dan kabupaten/kota) sejak 2009 serta wawancara non-penulis lainnya dengan pengalaman yang sama di lingkungan BPS.

\section{HASIL DAN PEMBAHASAN}

Estimasi PDRB sektor jasa-jasa memiliki kelemahan dalam ketersediaan data atau indikator sehingga kualitas penghitungannya tidak sebaik PDRB sektor barang (Pertanian, Kehutanan dan Perikanan (Kategori A), Pertambangan dan Penggalian (Kategori B), Industri Pengolahan (Kategori C), Pengadaan Listrik dan Gas (Kategori D), Pengadaan Air (Kategori E)). Perlakuan pada sektor jasa-jasa lebih menekankan pada pengambilan sampel dengan cara nonrandom dengan pertimbangan (judgement) penanggung jawab survei bahwa sampel terpilih mewakili populasi.

Metode data daring yang dapat diterapkan pada sektor jasa-jasa mencakup indikator produksi dan harga dari komoditas jasa untuk kalkulasi output. Selanjutnya biaya antara yang diperoleh dari 
online survei tersebut diolah sebagai faktor pengurang output sehingga diperoleh NTB (Nilai Tambah Bruto) yang merupakan ukuran yang nilai yang diciptakan melalui proses produksi. Format dan daftar pertanyaan dalam supplementary survey ini disusun hampir sama dengan kuesioner survei khusus, yaitu Survei Khusus Triwulanan Neraca Jasa (SKTNP) yang dilaksanakan BPS secara triwulanan dan SINASI (Survei Neraca Terintegrasi Daring/Online yang pertama kali diimplementasikan pada tahun 2020. Secara konseptual, supplementary ini memiliki konsep dan definisi yang sama dengan survei-survei khusus, namun formatnya disesuaikan untuk survei tahunan dengan form online (Google Form, Voxco survey platform, Compport) atau membangun aplikasi form online sendiri dengan daftar pertanyaan indikator utama. Pertanyaan mengenai identitas atau informasi pokok usaha dapat dijadikan dalam satu penomoran, jenis lapangan usaha tidak dimasukkan dalam pertanyaan, mengkonversi tabel pertanyaan menjadi list pertanyaan, menyajikan keterangan mengenai konsep dan definisi secara padat dan jelas, serta menyediakan fasilitas lompat pertanyaan bila tidak berkaitan dengan usaha atau kegiatan ekonomi responden karena kecenderungan responden mengabaikan pertanyaan yang tidak relevan (Handscomb, dkk, 2016).

Metode data daring untuk estimasi PDRB dapat diterapkan pada provinsi maupun kabupaten/kota dengan jumlah sampel untuk survei sektor jasa-jasa yang belum representatif secara jumlah terhadap populasi usaha pada survei-survei khusus misalnya seperti di kawasan Maluku dan Papua untuk kategori industri jasa-jasa, yaitu Perdagangan Besar dan Eceran, Reparasi dan Perawatan Mobil dan Sepeda Motor (Kategori G), Transportasi dan Pergudangan (Kategori H) sub kategori Pergudangan, Penyediaan Akomodasi dan Makan Minum (Kategori I) sub kategori Makan Minum, Informasi dan Komunikasi (Kategori J), Real Estat (Kategori L), Jasa Perusahaan (Kategori M, N), dan Jasa Lainnya (kategori R, S, T, U). Grafik 1 menunjukkan perbandingan antara jumlah populasi usaha sektor jasa-jasa berdasarkan hasil SE2016 lanjutan dan sampel survei tahunan kategori beberapa sektor jasa di empat provinsi di kawasan Maluku dan Papua.

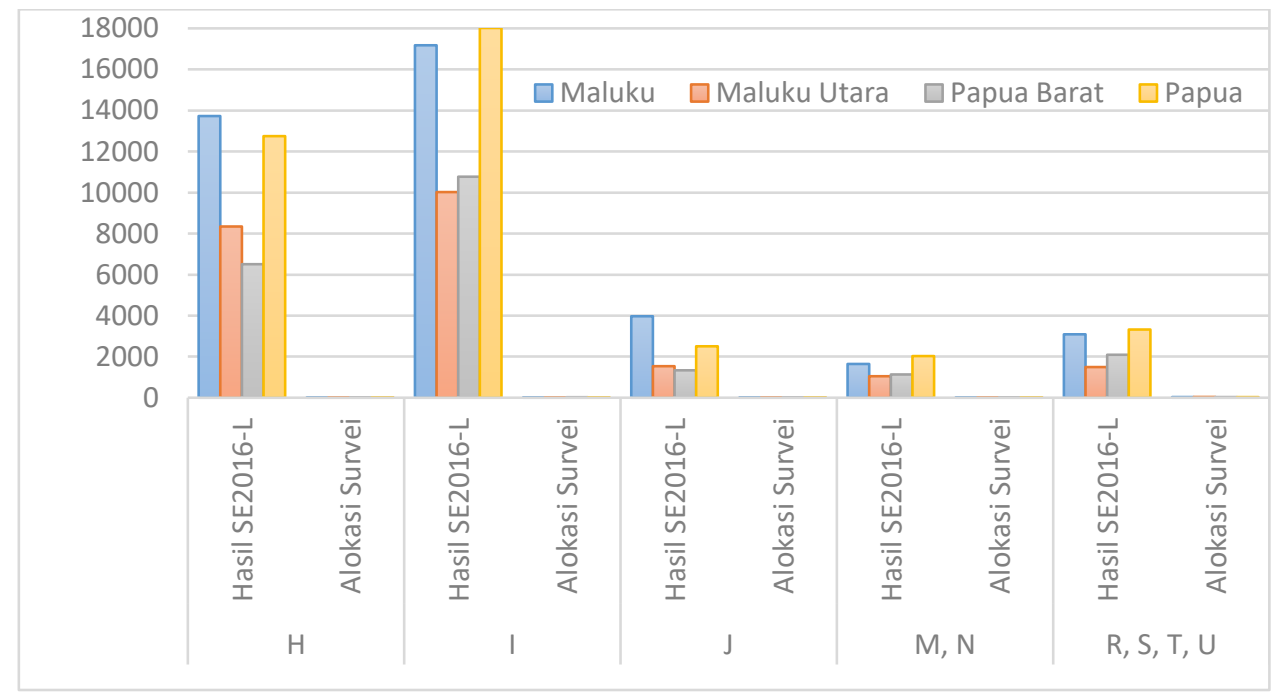

Gambar 1. Perbandingan jumlah populasi usaha hasil SE2016 dan alokasi survei tahunan untuk Provinsi Maluku dan Papua, Tahun 2020.

Dari grafik 1 terlihat bahwa jumlah responden sampel survei tahunan belum mencukupi untuk estimasi PDRB level regional (provinsi dan kabupaten/kota) sehingga perlu dilakukan penambahan sampel. Akan tetapi, keterbatasan biaya survei yang tersedia belum memungkinkan untuk pelaksanaan survei secara tatap muka/wawancara sehingga metode daring menjadi pilihan yang ideal untuk mengatasi permasalahan tersebut.

Penerapan data daring dilakukan untuk sampel tambahan dari responden kategori tersebut dapat menggunakan range $10 \%-30 \%$ dari jumlah sampel utama, tergantung pada keterbatasan sampel yang ada. Metode pemilihan sampel adalah purposive dengan melakukan profiling 
information pada responden potensial (Revilla, \& Ochoa, 2018). Tabel 1 menunjukkan daftar survei khusus yang ditargetkan untuk implementasi metode daring untuk peningkatan kualitas estimasi PDRB regional.

Tabel 33. Daftar Survei-survei khusus potensial penerapan metode Data Daring.

\begin{tabular}{|c|c|c|c|c|}
\hline No & Jenis Survei & $\begin{array}{c}\text { Waktu } \\
\text { Pengumpulan }\end{array}$ & $\begin{array}{l}\text { Persentase } \\
\text { Tambahan } \\
\text { Sampel }\end{array}$ & Profiling Responden \\
\hline 1. & $\begin{array}{l}\text { Survei Khusus Triwulanan } \\
\text { Neraca Produksi } \quad \text { (SKTNP) } \\
\text { Sektor Jasa }\end{array}$ & Triwulanan & $10 \%-30 \%$ & $\begin{array}{l}\text { Jenis kategori usaha, identitas } \\
\text { pokok usaha, pernah/tidak menjadi } \\
\text { responden survei selain survei } \\
\text { khusus BPS, time series indikator } \\
\text { produksi dan harga }\end{array}$ \\
\hline 2. & $\begin{array}{l}\text { Survei Neraca Terintegrasi } \\
\text { Daring (SINASI) }\end{array}$ & Tahunan & $10 \%-30 \%$ & $\begin{array}{l}\text { Jenis kategori usaha, identitas } \\
\text { pokok usaha, pernah/tidak menjadi } \\
\text { responden survei selain survei } \\
\text { khusus BPS, time series indikator } \\
\text { produksi dan harga }\end{array}$ \\
\hline
\end{tabular}

Sumber: penulis

\section{Tantangan Penerapan Data Daring dalam Estimasi PDRB}

Penerapan metode daring tentunya memiliki beberapa tantangan yang dapat mempengaruhi manfaat yang diharapkan, yaitu diantaranya:

1) Respon rate yang rendah

Umumnya survei online memiliki tingkat respon sampel yang cenderung rendah dibandingkan survei dengan wawancara kuesioner secara tatap muka dan melalui telepon (Devkota, dkk, 2007). Dengan kata lain, faktor penting yang dipertimbangkan jenis survei tersebut adalah tingkat responsivitas yang diperoleh (Nair \& Adams, 2009) karena survei melalui daring ini menitikberatkan pada metode non-probability yang rentan terhadap tingkat partisipasi (Sparrow \& Curtice, 2004; Darcy dan Wheaton, 2004, Van Selm \& Jankowski, 2006 dalam Callegaro, dkk (2014)). Metode konvensional memungkinkan adanya interaksi persuasif dengan responden secara langsung, sedangkan dalam metode daring sulit untuk memperkirakan respon rate dari calon responden secara akurat karena tergantung pada besarnya usaha dalam mempengaruhi calon responden untuk menyelesaikan online survei (Topp dan Pawloski, 2002, Wright, 2005).

2) Tingkat keamanan data

Keengganan target responden dalam penerapan pengumpulan data melalui daring terutama karena faktor keamanan data mengingat sensivitas pertanyaan yang terkait dengan kegiatan usaha, yaitu indikator produksi (nilai produksi/pendapatan) dan harga (harga komoditas). Menggunakan platform digital untuk menginput informasi yang bersifat rahasia termasuk beresiko tinggi dengan serangan kejahatan cyber karena jejak digital yang ditinggalkan. Tingkat keamanan menjadi isu utama dalam berbagi data yang memiliki tingkat privasi (Persia dan D'Auria, 2017). Pengumpulan data dengan metode daring ini akan memungkinkan adanya proses transfer data secara langsung melalui media online sehingga keamanan data menjadi rentan (Khadam, dkk, 2020).

3) Reliabilitas dan validitas data yang dihasilkan

Survei melalui daring berbasis based-internet survey sehingga memiliki potensi untuk bias (Hewson, 2016 dalam Fielding, dkk (2016)) karena dianggap metode penelitian online kurang representatif. Misalnya untuk responden sub kategori Perdagangan Besar dan Eceran yang terpilih dengan purposive method seharusnya memiliki market share yang relatif dominan dengan populasi sektor ini yang cukup besar. Sedangkan untuk memperoleh informasi mengenai jumlah populasi ini cukup sulit selain dari Sensus Ekonomi. Kerangka sampel perlu dibangun untuk meningkatkan tingkat akurasi data yang dihasilkan dari pemilihan sampel yang bersifat random. Akan tetapi, metode daring dengan 
non-probability sampling akan menciptakan peluang bias yang meningkat (Mercer, 2018). Reabilitas data online untuk analisis juga cenderung rendah karena adanya kekhawatiran dibalik faktor motivasi responden dalam menjawab pertanyaan (Gao, House dan Xie, 2013, Tourangeau, Rips, dan Rasinski, 2000 dalam Toma, Heinrich, dan Bauer, 2011). Lebih lanjut, penelitian Gao, dkk (2013) mengungkapkan bahwa kualitas data daring secara signifikan dipengaruhi oleh pandangan responden terhadap pentingnya pengumpulan data tersebut. Sampel pengumpulan data melalui daring adalah sebagai data pendukung sampel utama sehingga proporsi sampel terhadap populasi relatif tinggi dalam meningkatkan akurasi data.

\section{Prospek Pemanfaatan Data Daring dalam Estimasi PDRB}

Meskipun implementasi data daring memiliki permasalahan fundamental, namun survei jasajasa yang menggunakan metode ini memiliki prospek yang tinggi dalam meningkatkan keakuratan estimasi PDRB regional karena beberapa potensi manfaat yang dapat dijabarkan sebagai berikut.

1) Tidak memerlukan biaya besar dan waktu yang lama

Tidak seperti survei-survei khusus yang dilaksanakan oleh BPS Provinsi dan Kabupaten/Kota untuk memperoleh indeks produksi dan biaya antara sebagai komponen utama estimasi PDRB regional, pelaksanaan supplementary survey melalui daring akan menguntungkan dari segi biaya dan waktu (Hewson, 2016) dibandingkan menggunakan kuesioner. Biaya yang dihabiskan untuk pengumpulan data daring jauh lebih rendah (Handscomb, dkk, 2016, Darcy dan Wheaton, 2004). Selain itu, waktu untuk pengumpulan data lebih cepat sehingga rasio Biaya Antara (BA) atau rasio NTB (Nilai Tambah Bruto) misalnya dapat diupdate setiap tahun dengan kontinuitas pengumpulan data melalui daring setiap triwulan dan tahunan. Kedua hal ini akan dapat dicapai bila responden dalam survei bersifat panel (Callegaro, dkk, 2014).

2) Aksesibilitas survei dan waktu pengolahan data lebih cepat

Pengumpulan data melalui daring dapat diakses kapan saja dan dimana saja. Responden dapat mengisi kuesioner online melalui berbagai media seperti smartphone, tablet, notebook dan PC/laptop (Setiawan, 2012). Selanjutnya ini akan mempermudah proses input dan pengolahan data karena data dikumpulkan langsung dari responden ke dalam database (Topp dan Pawloski, 2002). Proses transfer data melalui daring juga tergolong cepat (Drewes, 2014). Bahkan metode daring dapat memungkinkan data entri otomatis melalui aplikasi form online (Darcy dan Wheaton, 2004).

3) Sebagai support analysis untuk perekonomian wilayah

Mengingat data sektor-sektor jasa lebih sulit diperoleh dibandingkan data sektor barang, supplementary survey melalui daring dapat dijadikan sebagai gambaran awal untuk analisis trend-based data (estimasi yang dilakukan dari data sebelumnya menggunakan moving average, metode rasio pertumbuhan atau judgement (Holdren, 2014)). Untuk itu, manfaat pengumpulan data melalui daring lebih tinggi bila responden target dilakukan secara time series. Hal ini dikarenakan pengumpulan data melalui daring yang konsisten akan membantu dalam memahami sektor-sektor jasa pada wilayah tersebut. Dengan demikian, estimasi PDRB regional akan lebih baik dibandingkan menggunakan faktor input yang diperoleh untuk level nasional. 


\section{KESIMPULAN}

Penerapan metode data daring yang digunakan untuk estimasi PDRB regional terbatas hanya untuk penambahan cakupan sampel survei-survei khusus dan target responden yang dipilih secara purposive dengan memperhatikan pangsa pasar yang dimiliki oleh responden tersebut terhadap perekonomian suatu wilayah. Untuk memaksimalkan tujuannya perlu dilakukan modifikasi pertanyaan pada kuesioner tergantung pada jenis industri jasa yang diestimasi. Meskipun supplementary survey dengan metode daring untuk pendukung penghitungan PDRB regional khusus sektor-sektor jasa akan memiliki permasalahan dalam implementasinya, namun cara ini juga akan membawa potensi manfaat untuk peningkatan akurasi estimasi PDRB jika dilakukan dengan baik. Akan tetapi, perlu dilakukan studi mendalam mengenai design sampling yang tepat dan kalibrasi metode daring yang akurat agar implementasinya lebih reliabel dan valid.

\section{UCAPAN TERIMA KASIH}

Terimakasih kepada Badan Pusat Statistik Provinsi Papua Barat terutama Bidang Neraca Wilayah dan Analisis Statistik yang memberikan insight dan informasi pendukung dalam penyusunan paper. Terimakasih kepada Badan Pusat Statistik Kota Sorong atas dukungan dan asistensinya melalui diskusi mendalam untuk penyelesaian tulisan.

\section{DAFTAR PUSTAKA}

Callegaro, M., et.al. (2014). Online panel research: a data quality perspective. West Sussex, England : John Wiley \& Sons

Callegaro, M., Lozar Manfreda, K. and Vehovar, V. (2015). Web Survey Methodology. London: Sage Publications.

Chenicheri Sid Nair \& Phillip Adams. (2009) Survey Platform: A Factor Influencing Online Survey Delivery and Response Rate, Quality in Higher Education, 15:3, 291-296, doi: $10.1080 / 13538320903399091$

Darcy, H. G., \& Wheaton, J. E. (2004). Online data collection: Strategies for research. Journal of Counseling and Development : JCD, 82(4), 387-393. doi:http://dx.doi.org/10.1002/j.15566678.2004.tb00325.x

Devkota, N., Paudel, K. P., Fannin, J. M., Hall, L. M., \& Caffey, R. H. (2007). Calibrating online survey sample for economic impact analysis. St. Louis: Federal Reserve Bank of St Louis. Retrieved from https://search.proquest.com/docview/1697526808?accountid $=12528$

Dong, L., Chen, S., Cheng, Y., Wu, Z., Li, C., \& Wu, H. (2017). Measuring economic activity in china with mobile big data. EPJ Data Science, 6(1), 1-17. doi:http://dx.doi.org/10.1140/epjds/s13688017-0125-5.

Drewes, F. (2014). An empirical test of the impact of smartphones on panel-based online data collection. 367-386 pp. In Callegaro, M., et.al. Online panel research a data quality perspective. John Wiley \& Sons, England.

Duan, W., Wang, Q., Verhulst, R., \& Xu, Y. (2019). Scalable online survey framework: From sampling to analysis. Ithaca: Cornell University Library, arXiv.org. Retrieved from https://search.proquest.com/docview/2246539118?accountid $=12528$

Fielding, N. G., Lee, R. M., \& Blank, G. (Eds.). (2016). The sage handbook of online research methods. ProQuest Ebook Central. Retrieved from http://ebookcentral.proquest.com

F. Persia and D. D'Auria, "A Survey of Online Social Networks: Challenges and Opportunities," 2017 IEEE International Conference on Information Reuse and Integration (IRI), San Diego, CA, 2017, pp. 614-620, doi: 10.1109/IRI.2017.74.

Gittelman, S. H., Thomas, R. K., Lavrakas, P. J., \& Lange, V. (2015). Quota Controls in Survey Research. Journal of Advertising Research, 55(4), 368-379. https://doi.org/10.2501/JAR-2015020

Handscomb, L., Hall, D. A., Shorter, G. W., \& Hoare, D. J. (2016). Online data collection to evaluate a theoretical cognitive model of tinnitus. American Journal of Audiology (Online), 25(3), 313-317. doi:http://dx.doi.org/10.1044/2016_AJA-16-0007 
Holdren, A. (2014, June). Gross domestic product and gross domestic income (BEA Briefing). Retrieved from https://www.apps.bea.gov

Khadam, U., Iqbal, M. M., Alruily, M., Al Ghamdi, M.,A., Ramzan, M., \& Almotiri, S. H. (2020). Text data security and privacy in the internet of things: Threats, challenges, and future directions. Wireless Communications \& Mobile Computing (Online), 2020, 15. doi:http://dx.doi.org/10.1155/2020/7105625

Moreh, C. (2019). Online survey design and implementation: Targeted data collection on social media platforms. SAGE Research Methods Cases. doi:10.4135/9781526479709

Rany, A.P., Farhani, S.A., Nurina, V.R., Pimada, L.M. (2020). Tantangan Indonesia dalam mewujudkan pertumbuhan ekonomi yang kuat dan pembangunan ekonomi berkelanjutan melalui indonesia green growth program oleh bappenas. Jurnal Ilmu Ekonomi dan Pembangunan, 20(1): 63-73.

Revilla, M., \& Ochoa, C. (2018). Alternative methods for selecting web survey samples. International Journal of Market Research, 60(4), 352-365. https://doi.org/10.1177/1470785318765537.

Taufik, T., Ayuningtyas, E. A. (2020). Dampak pandemi covid 19 terhadap bisnis dan eksistensi platform online. Jurnal Pengembangan Wiraswasta, 22(1): 21-32.

Terhanian, G., Bremer, J., Olmsted, J., \& Jiqiang Guo. (2016). A process for developing an optimal model for reducing bias in nonprobability samples. Journal of Advertising Research, 56(1), 14-24. https://doi.org/10.2501/JAR-2016-009.

Toma, B., Heinrich, D., \& Bauer, H. H. (2011). True lies in online research: how to determine accuracy in web surveys. Advances in Consumer Research, 38, 874-875.

Topp, N. W., \& Pawloski, B. (2002). Online data collection. Journal of Science Education and Technology, 11(2), 173-178. doi:http://dx.doi.org/10.1023/A:1014669514367.

Setiawan, T.P. (2012). Survei Online Penunjang Penelitian Praktis Dan Akademis. Prosiding Seminar Nasional Teknologi Informasi \& Komunikasi Terapan 2012 (Semantik 2012). 2012. INFRM.

Wright, K.B. 2005. Researching Internet-Based Populations: Advantages and Disadvantages of Online Survey Research, Online Questionnaire Authoring Software Packages, and Web Survey Services, Journal of Computer-Mediated Communication, 10(3). https://doiorg.ezproxy.lib.monash.edu.au/10.1111/j.1083-6101.2005.tb00259.x 